\title{
Are There Metrics for MOOCS From Social Media?
}

\author{
Alan Ruby, Laura Perna, Robert Boruch, and Nicole Wang \\ University of Pennsylvania
}

\begin{abstract}
Since "the year of the MOOC" in 2012, the effectiveness of massive open online courses (MOOCs) has been widely debated. Some argue that MOOCs are not an effective mode of instructional delivery because of low completion rates. In the interest of developing alternative indicators of performance this study draws from recent efforts to measure engagement in social media, as well as from research on indicators of student engagement in traditional college courses. Using data from 16 Coursera MOOCs offered by the University of Pennsylvania we calculate standardized access rates for lectures and assessments. While these indicators have clear limitations as measures of educational progress they offer a different, more nuanced understanding of the level and nature of users' engagement with a MOOC. This paper shows that a very small share of users takes up available opportunities to access course content but notes that the standardized access rates compare favorably with those for social media sites and with response rates to large-scale direct mail marketing programs. For MOOC providers and platform managers, indicators like the ones developed in this study may be a useful first step in monitoring the extent to which different types and combinations of activities may be providing better opportunities for learning.
\end{abstract}

\section{Introduction}

Since "the year of the MOOC" in 2012, the effectiveness of massive open online courses (MOOCs) has been widely debated. Some argue that MOOCs are not an effective mode of instructional delivery because of low completion rates. For example Perna et al. (2014) found fewer than $10 \%$ of those registered for "first-generation" MOOCs at the University of Pennsylvania completed the course. Completion rates were low, regardless of whether users followed the instructor's suggested pattern of 
experiences or chose the order to access learning materials. Other studies have reported similarly low completion rates (e.g., MOOCs @Edinburgh Group, 2013; Ho et al., 2014).

Using completion rates to gauge performance is consistent with conventional approaches to quantifying student behavior in a course of study. Enrollment, progress, and completion were commonly measured characteristics of early models of education systems (Stone, 1970; King, 1972) and enrollment and progress data recur in the OECD's Education at a Glance (OECD, 2014) statistical series.

Completion of a course is only a partial indicator of a MOOCs' performance or student outcomes. Some advocates, such as Koller et al. (2013), stress low completion rates can still result in large numbers of beneficiaries, given the very high number of users who register for a course. Moreover, completion may not be a MOOC user's goal (Koller et al., 2013) and focusing on completion could obscure the possibility that intermittent interaction with a MOOC may produce user benefits (Haggard, 2013; Ho et al., 2014). Conventional indicators of progress may be "ill-suited" to the environment or course design of a MOOC (Hoffman and Fodor, 2010, p. 42), as MOOCs allow episodic and partial involvement as well as ordered and sequential movement within a course.

Recognizing that measures of completion are "fairly blunt instruments when it comes to making sense of student interaction, engagement and learning," Coffrin et al. (2014, p. 85) focused on identifying categories of users in MOOCs, based on users' levels of engagement in course content. Their analyses revealed three categories of users: "auditors"-those who watch content but do not do assessments; "active" learners - those who completed at least one assessment; and "qualified" learners-those who watched content, completed an assessment, and scored well. This effort to categorize users in MOOCs aligns with attempts to sort social media users along a continuum of "visitors," i.e., those who see the Internet as a tool, and "residents," those who use the internet as a social space (Wright et al., 2013; White and Le Cornu, 2010).

This study explores patterns of engagement in MOOCs, drawing from efforts to measure engagement in social media, as well as from research on indicators of student engagement in MOOCs and traditional college courses. In particular, our interest is in creating a measure of the rate of taking up MOOC learning opportunities that is easy to calculate and interpret. We explore the utility of several potential indicators of engagement in a MOOC by using data from 16 Coursera MOOCs offered by the University of Pennsylvania.

Indicators of engagement akin to those used in social media may be useful because of similarities between MOOCs and social media sites. For instance, MOOCS and social media use "web based technologies to create...interactive platforms via which individuals and communities share...(c)o-create, discuss and (possibly) modify...content” (Keitzmann et al., 2011, p. 241). The technology on which MOOCs and social media sites depend makes communication among users easy and inexpensive. Both MOOCs and social media sites are usually freely accessible and allow users to access the sites when they wish; the user controls the duration, rate, frequency and order of interactions. Both offer opportunities for different levels of activity allowing users to exchange information and view, manipulate and create content. Both put a premium on reaching large numbers of people and retaining their interest.

Social media sites can be thought of as learning environments or "passionate affinity spaces" (Gee and Hayes, 2011, p.69) where people with shared interests exchange ideas and information freely, regardless of prior experience and expertise, age, gender, location or wealth (Gee 2013a, p. 175). Social media sites use a "participation metaphor" (Sfard 1998, p. 6) of learning and engagement where the goal is community building and the emphasis is on belonging to the group and participating in its activities. While the Coursera MOOCs share some of the characteristics of affinity spaces, many of the courses we study emphasized individuals as recipients of content provided by experts with a goal of mastery, more akin to Sfard's metaphor of learning as acquisition (p. 7). Some courses like Modern Poetry (MoPo) 
placed great weight on participation, peer review, collegiality and exchange. As Sfard argues there is a "case for the plurality of metaphors" (p.11) and, when the technology is still evolving, as in the case of MOOCs and measurement of MOOC effectiveness, exploring activity measures like those used by social media is a potentially fertile field of inquiry.

\section{Engagement}

The literature on engagement and learning illustrates the complexity of these constructs. Azevedo (2015) points to the scope and diversity of approaches to delineating and quantifying engagement. In his commentary on six articles representing "the various theoretical, methodological, and analytical challenges," Azevedo begins by declaring that "engagement is one of the most widely misused and over-generalized constructs" (p. 84). Azevedo concludes by arguing for greater attention to "process data" as this "will lead to advances in models...analytical techniques and...instructional recommendations” (p. 93).

Reflecting an interest in process, higher education institutions commonly emphasize "engagement" as a mechanism for improving the college experience and increasing graduation rates (see Price \& Tovar, 2014). Attention to engagement is grounded in the work of scholars such as Tinto (1975, 1987), Astin (1984) and Kuh and his colleagues (2006) who identify behaviors that arguably enhance learning. Engagement, for example, can be defined as the "time and effort students devote to activities that are empirically linked to desired outcomes... and what institutions do to induce" participation in these activities (Kuh, 2009b, p. 683). Engagement is assumed to be a key mechanism for promoting learning as it "builds the foundation of skills and dispositions that people need to live a productive satisfying life" (Kuh, 2009a, p. 5). It includes interactions with learning materials, other learners, faculty, and cocurricular activities.

Student engagement research often focuses on on-campus and face-to-face instructional activities but some scholars have considered the relationship between engagement and outcomes in on-line courses (Coates, 2007; Chen, Gonyea, \& Kuh, 2008; Robinson \& Hullinger, 2008), in learning management systems (Beer et al., 2010) and in social networks (Thoms and Eryilmaz, 2014). As an example, Robinson and Hullinger (2008) used a version of the National Survey of Student Engagement (NSSE) to explore variations in engagement of students enrolled in at least one completely on-line course. The results suggest variations in engagement are associated with students' academic performance, academic major, and age, and faculty creating "purposeful course designs that promote interaction, participation, and communication in the online learning environment” (Robinson \& Hullinger, 2008, p.107).

Although measured much more simply than in on-line or e-learning environments, engagement is also a key criterion for assessing the effectiveness of social media sites as marketing tools (Social Bakers, 2013). Each visit to a site or a page is an engagement, for instance, and represents an opportunity to place new content before a potential purchaser. This type of engagement measure is used to assess the effectiveness of marketing strategies for products as diverse as luxury shoes (PR newswire, 2013) and furniture (French, 2012).

Although social media networks offer different opportunities for engagement (Dunham, 2014), many use a common approach to assess engagement. The goal is capturing consumer actions and behaviors beyond the simple act of viewing content (Hollebeek, Glynn \& Brodie, 2014). These approaches assume that success on social media platforms like Facebook is "not primarily a matter of amount of fans." Activity is more important: "likes, comments and shares are the fuel of vitality" (Eyl, 2013, p. 1). User engagement with content on a social media site is "likely to generate commitment," brand loyalty, and repeat business (Hoffman \& Fodor 2010, p. 46.) 
Typically, approaches to measuring engagement in social media aggregate the number of "Likes," "Posts," and "Shares," or things like replies on Twitter and comments on LinkedIn and Instagram, for a specific period. This number is then related to the number of followers or fans during the same period. Averaging these rates across days or weeks produces a "mean engagement rate." Calculating activity per user, for instance, recognizes the dynamic nature of social media and is an indicator of how many people are "connecting with your brand and how often" and how many times they draw attention of others to the content or item (Ken, 2014, p. 2).

Engagements rates make it easier to understand the large and complex activity of many social media sites, partly by sifting out one-time visitors and passive followers. In an analysis of more than 4.9 million posts over three months on 60,000 Facebook pages, Eyl (2013) found most sites have "very low" engagement rates. Half of all sites had rates of " 0.002 interactions per fan per day." In essence, engagement rates in social media are the sum of individuals' discrete actions that change a screen view, standardized to some measure of the population. This standardization allows comparisons of engagement rates between courses or segments of courses.

While there is a commercial driver behind much of the attention to engagement rates in social media settings, the activities measured are essentially acts of participation, with the user doing something in relation to content on a site. This approach echoes Sfard's (1998) idea of seeing learning in terms of "participation," as individual "learners contribute to the existence and functioning of a community of practitioners" (p. 6). It also indicates how large numbers of individuals organize or "self-regulate" learning activities which "is of particular importance in relatively open learning environments... where learning is enhanced by digital technologies” (Steffens, 2015, p. 49).

\section{Applying Engagement Rates to MOOCS}

Measures of engagement in social media are less sophisticated than measures that have been developed to understand engagement in on-campus courses and some on-line courses. Nonetheless, applying the basic notions of social media engagement metrics to MOOCs may provide useful insights into the activities of MOOC users. The first generation of Coursera MOOCs was usually neither creditbearing nor credentialed. They were less formal learning environments with flexibility in terms of time spent or required, order and rate of progress through materials, and involvement in assessment activities. As such, they are akin to the largely informal online learning environments like social media sites and digital games and fan sites which "connect playing and learning to social interaction and mentoring" (Gee, 2013b, p.18). Although MOOCs use formal, frequently didactic, instructional methods, they operate sufficiently like fully informal environments like Facebook or Instagram to make the use of social media metrics worth exploring.

This study answers the question: how often do users access content, be it a course lecture, a quiz, or another assessment? Applying measures from social media to address this question accommodates asynchronous access and differences in an individual's intentions. It also places user behavior at the heart of understanding the extent to which users access large-scale open online course content. This study does not classify users into "types," assuming that users may behave differently at different times and circumstances. In this study, the access rate quantifies the act of opening a lecture or quiz, activities that precede and may presage learning. We call these measures 'access rates' to avoid inferring any user behavior beyond the act of opening a page view. We are measuring the frequency of a basic activity, how often the individual's screen view changes, that is a precursor to constructive and interactive learning activities like generating something that is not in the material presented or confirming or debating another's proposition (Chi 2009, pp.77-83) 


\section{An Example: Access Rates for Penn’s First-Generation Coursera Offerings}

We used this approach to examine user access in 16 Coursera courses taught for the first time by faculty at the University of Pennsylvania between June 2012 and July 2013. The courses varied in field of study, design, length and number of access opportunities.

We consider the extent to which users access four types of instructional materials: lectures; quizzes embedded in lectures; stand-alone quizzes; and open-ended questions. Our approach gives equal weight to different activities - that is, accessing a lecture counts the same as responding to an open-ended question or attempting a multiple-choice quiz. This approach avoids making assumptions about the type of activity that "best" promotes learning in an online environment although Chi's (2009) taxonomy of active, constructive and interactive learning suggests simply viewing a lecture is a less engaged activity as compared to identifying the right answer or creating original text. We do not consider activities such as posting a message to a discussion forum, as Coursera did not provide us with access to these data and because of challenges associated with interpreting these data (as discussed by Brinton et al., 2013). We focus instead on exploring indicators of engagement that instructors can easily adopt and that can be replicated across large numbers of courses at little cost. We do not perform statistical tests as the analyses describe data from the population, not a sample. Moreover, with the high number of cases in the analyses, all statistical tests would be statistically significant.

\section{Two Indicators of User Activity}

In what follows we use two indicators, one that is aggregated across the 16 courses and one that pertains to each course separately. The first indicator, access rate per user, is the sum of the number of times a user accessed any of the four types of activities offered in the course, divided by the number of users. We define a user as someone who registers for a course between the dates a course opens and two months after the course ended. This indicator recognizes that a user may access a lecture and some assessments multiple times.

The second indicator, the standardized access rate, adjusts for the number of different access opportunities a course offers. The rate is calculated as the number of accesses per user divided by the number of access opportunities offered. The denominator is effectively the number of "personopportunities" akin to "person-years" or "disability adjusted life-years" used by health economists and epidemiologists for over 30 years (Kromann, \& Green, 1980; Anand, \& Hanson, 1997; Bhupathiraju et al., 2014). The standardized access rate sums all of the chances a person has to learn or at least look at new content in a course.

\section{Penn Course Access Rates}

Table 1 (next page) shows that, across the 16 courses, more than 710,000 users had just over 1,100 opportunities to access lectures, stand-alone quizzes, embedded quizzes and open-ended questions. Users took up these opportunities nearly 13 million times. Of the nearly 13 million access behaviors more than 9.2 million were tied to lectures and nearly 3.7 million were tied to assessments.

Across the 16 courses, a given user accessed content an average of 18.2 times. The access rate for lectures (13 per user) is higher than the access rate for assessments (5.2 per user). Access rates also vary by type of assessment. The rate falls from 3.4 accesses per user for quizzes embedded in lectures, to 1.6 for standalone quizzes, to 0.2 for open-ended questions. 
Table 1. Access Rates Aggregated Across Courses.

\begin{tabular}{|c|c|c|c|c|c|}
\hline Opportunities & $\begin{array}{l}\text { Number of } \\
\text { Registrants } \\
\text { (A) }\end{array}$ & $\begin{array}{l}\text { Number of } \\
\text { Times } \\
\text { Accessed } \\
\text { (B) }\end{array}$ & $\begin{array}{l}\text { Access } \\
\text { Rate (B) / } \\
\text { (A) }\end{array}$ & $\begin{array}{l}\text { Number of } \\
\text { Access } \\
\text { Opportunities } \\
\text { (C) }\end{array}$ & $\begin{array}{l}\text { Standardized } \\
\text { Access Rate } \\
{[(\mathrm{B} / \mathrm{A}) / \mathrm{C}]}\end{array}$ \\
\hline Registrants & 710,385 & & & & \\
\hline Total & & $12,946,959$ & 18.2 & 1,131 & 0.016 \\
\hline Lectures & & $9,251,884$ & 13.0 & 718 & 0.018 \\
\hline Assessments & & $3,695,075$ & 5.2 & 413 & 0.013 \\
\hline Total Assessments & & $3,695,075$ & 5.2 & 413 & 0.013 \\
\hline Embedded quiz & & $2,439,680$ & 3.4 & 186 & 0.018 \\
\hline Standalone quiz & & $1,127,228$ & 1.6 & 171 & 0.009 \\
\hline $\begin{array}{l}\text { Open-ended } \\
\text { question }\end{array}$ & & 128,167 & 0.2 & 56 & 0.003 \\
\hline
\end{tabular}

While interesting, these rates do not take into account the number of instructor-created access opportunities in a course. To control for this variation, Table 1 also shows the "standardized access rate." Across all opportunities, the standardized access rate averages 0.016. The standardized access rate is somewhat higher for lectures (0.018) than for assessments (0.013). The standardized access rate also varies based on type of assessment, falling from 0.018 for quizzes that are embedded in lectures, to 0.009 for stand-alone quizzes, to 0.003 for open-ended questions. The standardized lecture access rate (0.018) is roughly equivalent to the $2 \%$ average response rate for direct mail advertising sent to individuals (DMA 2012 \& Yoon \& Eckels 2013).

These aggregate numbers mask variations across courses. Table 2 (next page) shows that the average number of times a user accessed course content (that is, the access rate) varies across the courses by a factor of 5, ranging from a low of 7.3 in Rationing and Allocating Scarce Medical Resources to 35.4 in Gamification.

The average number of times a user accesses course content is not tied to the number of access opportunities. Five courses have 100 or more access opportunities (Gamification, Microeconomics, Calculus, Mythology, and Modern Poetry) but the access rates for these courses vary from 15.6 to 35.4. Among the seven courses with fewer than 50 access opportunities, access rates range from 7.3 to 24.8. Gamification and Modern Poetry have the same number (100) of opportunities, but Gamification has a much higher access rate (35.4 per user) than Modern Poetry (15.6). When we adjust access rates for the number of access opportunities, we continue to see considerable variation across courses. Table 2 shows standardized access rates ranging from 0.12 in Calculus and 0.14 in Genome Science to more than 0.6 in ADHD, Vaccines, and Pharmacy 101. The five-fold difference between the lowest and the highest standardized access rates is important because it shows that some courses engage learners more than others. There may be some instructional design choices that produce courses that engage learners more than others. These choices (preferred length of video or type of assessment, for example) could be revealed by more focused research within the highest and lowest rating courses. Our set of courses is too small and too different in design, length, audience, content and degree of difficulty to allow us to identify patterns or draw conclusions about the instructional choices that produce the greatest engagement. 
Table 2. Access Rate for Each Course

\begin{tabular}{|c|c|c|c|c|c|c|}
\hline Course & $\begin{array}{l}\text { Number of } \\
\text { Registrants } \\
\text { (A) }\end{array}$ & $\begin{array}{l}\text { Number } \\
\text { of Times } \\
\text { Accessed } \\
\text { (B) }\end{array}$ & $\begin{array}{l}\text { Access } \\
\text { (B) / } \\
\text { Users } \\
\text { (A) }\end{array}$ & $\begin{array}{l}\text { Number of } \\
\text { Opportunities } \\
\text { (C) }\end{array}$ & $\begin{array}{l}\text { Standardized } \\
\text { Access Rate } \\
{[\text { (B / A ) / C] }}\end{array}$ & $\begin{array}{l}\text { Lecture } \\
\text { Completion } \\
\text { Rate }\end{array}$ \\
\hline Gamification & 83,061 & $2,942,781$ & 35.4 & 100 & 0.35 & $18 \%$ \\
\hline ADHD & 25,995 & 645,180 & 24.8 & 36 & 0.69 & $15 \%$ \\
\hline Operations & 99,451 & $2,009,708$ & 20.2 & 94 & 0.21 & \\
\hline MicroEcon & 35,460 & 703,307 & 19.8 & 123 & 0.16 & $7 \%$ \\
\hline $\begin{array}{l}\text { Health } \\
\text { Policy }\end{array}$ & 30,592 & 562,686 & 18.4 & 42 & 0.44 & $10 \%$ \\
\hline Vaccines & 20,689 & 365,257 & 17.7 & 28 & 0.63 & $14 \%$ \\
\hline Calculus & 58,170 & 981,037 & 16.9 & 141 & 0.12 & $6 \%$ \\
\hline Myth & 63,545 & $1,042,949$ & 16.4 & 109 & 0.15 & $7 \%$ \\
\hline $\begin{array}{l}\text { World } \\
\text { Music }\end{array}$ & 35,132 & 566,101 & 16.1 & 73 & 0.22 & $6 \%$ \\
\hline ModPo & 39,654 & 617,055 & 15.6 & 100 & 0.16 & $6 \%$ \\
\hline Pharm101 & 24,582 & 370,331 & 15.1 & 23 & 0.66 & \\
\hline Design & 46,241 & 693,331 & 15.0 & 78 & 0.19 & $8 \%$ \\
\hline Cardiac & 44,168 & 647,433 & 14.7 & 41 & 0.36 & $14 \%$ \\
\hline Networks & 45,681 & 452,757 & 9.9 & 48 & 0.21 & $13 \%$ \\
\hline $\begin{array}{l}\text { Genome } \\
\text { Science }\end{array}$ & 33,154 & 251,593 & 7.6 & 55 & 0.14 & \\
\hline Rationing & 13,228 & 96,171 & 7.3 & 40 & 0.18 & $7 \%$ \\
\hline
\end{tabular}

\section{Access or Completion?}

Access rates offer a different view of the potential educational benefits of courses than completion rates. In earlier work with this same group of MOOCs, we speculated that relatively low completion rates may reflect, in part, user "curiosity, browsing and lack of interest or motivation to complete” (Perna et al., 2014 ). We calculated completion rates for populations of "registrants," those who signed up for the course when it opened and at any point up until two months after the last course component was released. ${ }^{1}$ We defined completion rates as the percentage of registrants accessing a lecture in the last week or module of a course and refer to them as "lecture completion rates" to distinguish them from completion rates of assessment activities.

\footnotetext{
${ }^{1}$ Refer to Perna et al (2014), for a complete description of the procedures used to define registrants and calculate lecture completion rates. For example, a registrant is a person who signed up for the course when opened and at any point up until two months after the last course component was released.
} 
Comparing standardized access rates with completion rates for lectures for the 13 courses with available data ${ }^{2}$ reveals a relationship between the two measures, albeit with some variability (see Figure 1). The generally positive relationship in Figure 1 is consistent with the assumption that 'engagement' (as measured here by standardized access rates) is positively related to completion. The implication is that standardized access rates can predict completion rates especially when the access rates are low. This relationship is illustrated by the clustering of low access and completion rates in the bottom left corner of Figure 1. As access rates increase, completion rates also increase but with greater variability as evidenced by the spread in the upper right quartile of Figure 1. But there is still a clear relationship between access and completion, as the correlation between access and completion rates is 0.81 . If one were to construe the obtained correlation as being from a sample of some hypothetical population (rather the entire population), the correlation would be statistically significant (different from zero) at the alpha=.001 level or less.

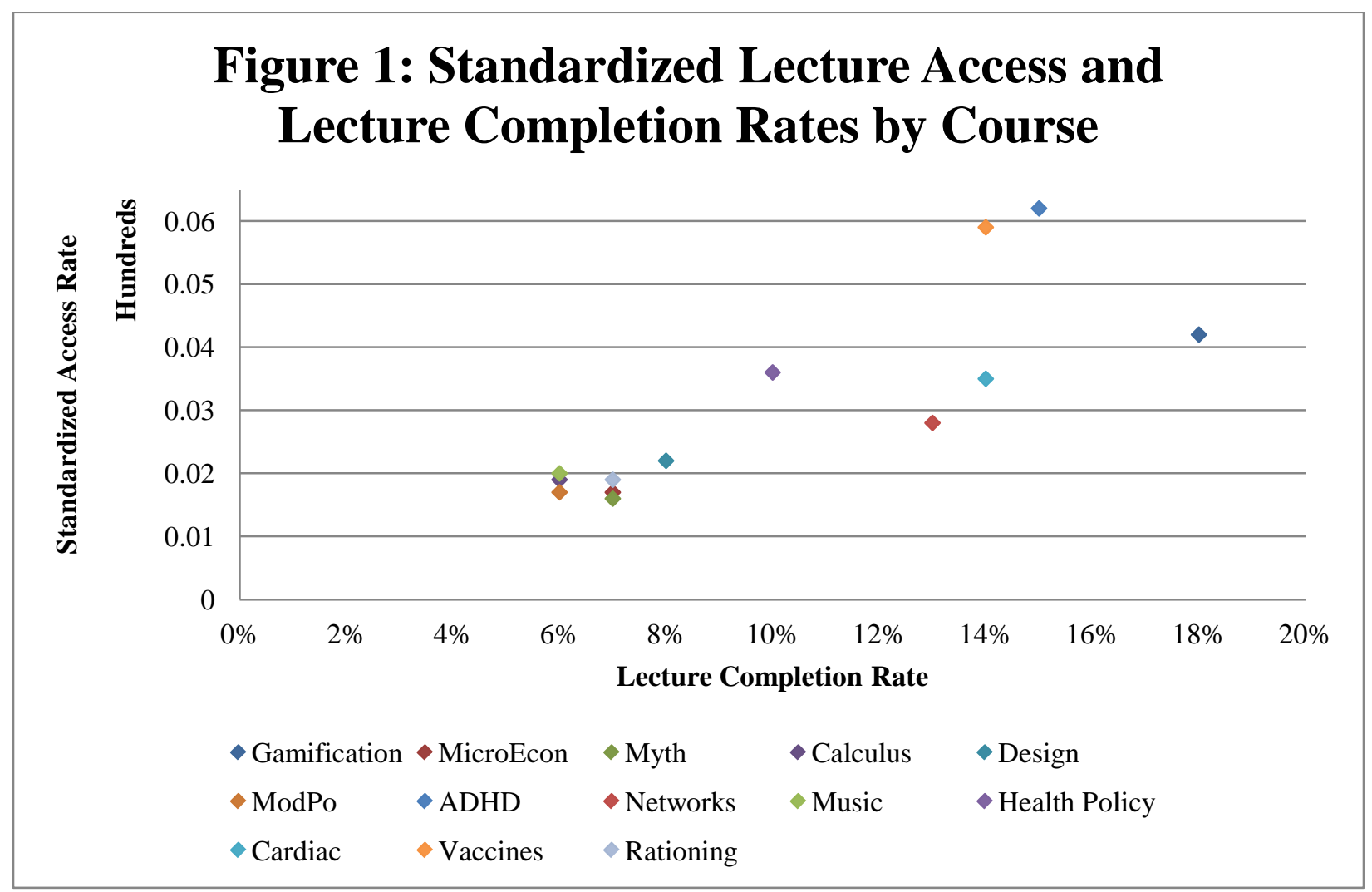

\section{Discussion}

The data show that a very small share of users takes up available opportunities to access course content. The standardized access rates used here compare favorably with those cited for many social media sites (e.g., Eyl, 2013) and with response rates to large-scale direct mail marketing programs (DMA, 2012). These results suggest MOOCs_at least in the form examined in this study_are operating like the

\footnotetext{
${ }^{2}$ We have lecture completion rates for thirteen of the sixteen courses. For three courses it was not possible to determine which lecture was the last in the sequence. See Perna et al (2014) for a more complete discussion of the implications of the available data for measurement of completion and other aspects of the analyses.
} 
informal environments of such social media sites as Facebook and Instagram despite the presence of more formal instructional methods.

The indicators of access in this study have clear limitations as measures of engagement in effective educational practices or educational progress. They do not measure learning, length of time spent on an activity, or other potentially useful dimensions of a user's experience with any set of content or assignment. They do not differentiate single and multiple views of the same material. They also do not take into account differences in course length or difficulty, or the quality of lecture presentation and assessment design. Nonetheless, by assessing the extent to which users are accessing course content rather than completing a course, access rates offer a different, more nuanced understanding of the level and nature of user engagement with a MOOC.

Although crude, these indicators of access proposed and used here also offer insights into how large numbers of users respond to different types of opportunities to engage with various forms of course content. Both the analyses of aggregated data and analyses of data that are disaggregated by course suggest users typically are more likely to access lectures than assessments. Users also tend to attempt quizzes embedded in lectures more readily than other assessments. In short, an instructor's choices about the array of opportunities appear to influence user activity. These findings build on the conclusion by Guo, Kim, and Rubin (2014) that the length of videos in Edx MOOCs influences participation, with shorter videos being "much more engaging" (p. 2). The difference between access rates for embedded quizzes and stand-alone quizzes suggests that even minimal additional effort or time is a deterrent; standalone quizzes require more effort. This conclusion is consistent with Chi (2009), who notes that the demands on the user of activities defined as "constructive" and "interactive" are more taxing, require more effort and concentration, or simply require more time-all which reduce 'take up' of the learning opportunities. For course providers and platform managers, indicators like those developed in this study may be a useful first step in monitoring the extent to which different types and combinations of activities may be providing better opportunities for learning. Access indicators can also be used in marketing courses to potential users. Access rates can also show people who are interested in monetizing MOOCs or using them as advertising vehicles the actual reach of particular courses and segments of courses. And perhaps most importantly for faculty and instructional designers, access rates may inform instructional design choices.

Social media engagement rates are evolving as the industry matures and as technology develops. With this evolution new metrics for assessing the effectiveness of large-scale online courses may emerge. In the interim, the indicators described in this paper can be used as an empirical foundation for making instructional choices that may increase course completion, as well as other measures of user-benefits and effectiveness of MOOC offerings.

\section{About the Authors}

Alan Ruby is a senior fellow at the Alliance for Higher Education and Democracy, Graduate School of Education, University of Pennsylvania, 3700 Walnut Street, Philadelphia PA 19130; alanruby@ gse.upenn.edu. His research focuses on globalization and higher education and secondary school reform in newly independent nations.

Laura W. Perna, PhD, is James S. Riepe Professor and Executive Director, Alliance for Higher Education and Democracy (AHEAD), at the University of Pennsylvania, 3700 Walnut Street, Philadelphia, PA 19104; lperna@gse.upenn.edu. Her research interests focus on understanding how social structures, educational practices, and public policies promote and limit college access and success, particularly for individuals from lower-income families and racial/ethnic minority groups. 
Robert F. Boruch, PhD, is University Trustee Chair Professor in the Graduate School of Education and the Statistics Department of the Wharton School at the University of Pennsylvania, 3700 Walnut Street, Philadelphia, PA 19104; robertb@gse.upenn.edu. His current research focuses on randomized controlled trials in different disciplines, big data, research ethics, and failure analysis.

Nicole Wang was a research fellow at the University of Pennsylvania, Graduate School of Education, she is now a PhD student in the Learning, Design, and Technology program at College of Education in Penn State University, 301 Keller Building, University Park, PA 16802. ; nwang@psu.edu.Her research focuses on MOOCs, quantitative analysis, evaluation, and big data.

\section{References}

Anand, S., \& Hanson, K. (1997). Disability-adjusted life years: a critical review. Journal of health economics, 16(6), 685-702.

Astin, A.W., (1984). Student involvement: a development theory for higher education. Journal of College Student Personnel, 25(4), 297-308.

Perna, L., Ruby, A., Boruch, R., Wang, N. Scull, J. Ahmad, S., \& Evans C. (2014). Moving through MOOCs: understanding the progression of users in massive open online courses, Educational Researcher, 43, 421-432.

Azevedo, R. ( 2015). Defining and measuring engagement and learning in science: conceptual, theoretical, methodological and analytical issues. Educational Psychologist. 50(1), 84-94.

Beer, C. Clark, K., \& Jones, D. (2010). Indicators of engagement. In C.H. Steel, M.J. Keppell, P. Gerbic \& S. Housego (Eds.), Curriculum, technology \& transformation for an unknown future. Proceedings ascilite Sydney 2010 (pp.75-86).

Bhupathiraju, S. N., Pan, A., Manson, J. E., Willett, W. C., van Dam, R. M., \& Hu, F. B. (2014). Changes in coffee intake and subsequent risk of type 2 diabetes: three large cohorts of U.S. men and women. Diabetologia, 57(7), 1346-1354.

Brinton, C.G., Lam, H., Chiang, M., Liu, Z., Jain, S., Wong, F. (2013, December). Learning about social learning in MOOCs: from statistical analysis to generative model. Unpublished paper.

Chen, P., Gonyea, R., \& Kuh, G. (2008). Learning at a distance: engaged or not. Innovate: Journal of Online Education, 4(3), 1-8.

Chi, M.T.H. ( 2009). Active-constructive-interactive: a conceptual framework for differentiating learning activities. Topics in Cognitive Science. 1. 73-105.

Coates, H. (2007). A model of online and general campus-based student engagement. Assessment \& Evaluation in Higher Education, 32(2), 121-141.

Coffrin, C., Corrin, L., de Barba, P., \& Kennedy, G. (2014, March). Visualizing patterns of student engagement and performance in MOOCs. In Proceedings of the Fourth International Conference on Learning Analytics and Knowledge (pp. 83-92). ACM.

DMA (2012). Direct mail response rates beat digital. http://www.dmnews.com/dma-direct-mail-repsonserates-beat-digital/article/245780/ 
Dunham, K., (2014). The beginner's guide to social media metrics: engagement. http://blog.hootsuite.com/beginners-guide-engagement

Eyl, S., (2013, February 13). Study on Facebook engagement and interaction rates. fanpage karma. Retrieved from http://blog.fanpagekarma.com/2013/02/13/facebook-engagement-interactionrates/

French, D., (2012). Reaching today’s buyers through social media. Furniture Today, 36(33).

Gee, J.P., (2013a). The anti-education era: creating smarter students through digital learning. New York: Palgrave MacMillan.

Gee, J.P., (2013b). Games for learning. Educational Horizons 19(4), 16-20.

Gee, J.P. \& Hayes, E.R. (2011). Language and learning in the digital age. New York: Routledge.

Guo, P.J., Kim, J., \& Rubin, R. (2014) How Video Production Affects Student Engagement: An Empirical study of MOOC Videos, L @ S 2014, March 4-5, Atlanta Georgia. http://dx.doi.org/10.1145/2556325.2566239.

Haggard, S., (2013). The maturing of the MOOC. Department of Business, Industry and Skills Research Paper No. 130.

Ho, A.D., Reich, J., Nesterko, S., Seaton, D.T., Mullaney, T., Waldo, J., \& Chuang, I. (2014). Harvard X and MITx: the first year of open online courses. Harvard X \& MITx Working Papers No.1.

Hoffman, D.L, \& Fodor, M., (2010). Can you measure the ROI of your social media marketing? MIT Sloan Management Review 52(1), 41-49.

Hollebeek, L.D., Glynn, M.S., \& Brodie, R.J., (2014). Consumer brand engagement in social media: conceptualization, development and validation. Journal of Interactive Marketing 28, 149-165.

Ken, D. (2014, March 15). Why engagement rate is more important than likes on your Facebook. Social media today. Retrieved from http://www.socialmediatoday.com/content/why-engagement-ratemore-important-likes-your-facebook

Kietzmann, J.H., Hermkens, K., McCarthy, I.P., \& Silvestre, B.S., (2011). Social Media? Get serious! Understanding the functional building blocks of social media. Business Horizons, 54, 241-251.

King, M.A. (1972). Primary and secondary indicators of education. In A. Shonfield and S. Shaw (eds.), Social indicators and social policy (pp. 53-66). London: Heinemann Educational Books.

Koller, D., Ng, A., Chuong, D., \& Chen, Z. (2013, May/June). Retention and intention in massive open online courses. Educause Review.

Kromann, N., \& Green, A. (1980). Epidemiological studies in the Upernavik district, Greenland. Acta Medica Scandinavica, 208(1-6), 401-406.

Kuh, G.D. (2009a). The national survey of student engagement: conceptual and empirical foundations. New directions for Institutional Research, 2009(141), 5-20.

Kuh, G.D. (2009b). What student affairs professionals need to know about student engagement. Journal of College Student Development. 50(6), 683-706. 
Kuh, G.D., Kinzie, I., Bridges, B.K., \& Hayek, J.C., (2006). What matters to student success: a review of the literature. Washington D.C.: National Postsecondary Education Cooperative.

MOOCs @ Edinburgh Group (2013). MOOCS @ Edinburgh 2013, Report \#1. University of Edinburgh. Retrieved from https://www.era.lib.ed.ac.uk/handle/1842/6683

OECD, (2014). Education at a glance 2014: OECD indicators. Paris: OECD Publishing.

Perna, L.W., Ruby, A., Boruch, R., Wang, N., Scull, J., Ahmad, S., \& Evans, C. (2014). Moving through MOOCs: understanding the progression of users in MOOCs. Educational Researcher, 43, 421432.

Price, D.V. \& Tovar, E. (2014). Student engagement and institutional graduation rates: identifying high impact educational practices for community colleges. Community College Journal of Research and Practice, 38(9), 766-782.

PR Newswire (2013, July 24). Engagement rates for Stuart Weitzman's international Facebook campaigns exceed industry average by more than 5000\%. Retrieved from http://www.prnewswire.com/news-releases/engagement-rates-for-stuart-weitzmans-internationalfacebook-campaigns-exceed-industry-average-by-more-than-5000-216736261.html

Robinson, C. C., \& Hullinger, H. (2008). New benchmarks in higher education: student engagement in online learning. Journal of Education for Business, 84(2), 101-109.

Sfard, A., (1998). On two metaphors for learning and the dangers of choosing just one. Educational Researcher, 27(2), 4-13.

Social Bakers, (2013, February 25). Engagement rate: a metric you can count on. Retrieved from http://www.socialbakers.com/blog/1427-engagement-rate-a-metric-you-can-count-on

Steffens, K. (2015). Competences, learning theories and MOOCs: recent developments in lifelong learning. European Journal of Education 51(1), 41-58.

Stone, R. (1970). Mathematical models of the economy and other essays. London: Chapman and Hall.

Thoms, B., \& Eryilmaz, E. (2014). How media choice affects learner interactions in distance learning classes. Computers \& Education, 75, 112-126.

Tinto, V., (1975). Dropout from higher education: a theoretical synthesis of recent research. Review of Educational Research 45(1), 89-125.

Tinto,V., (1987). Leaving college: rethinking the causes and cures of student attrition. Chicago: University of Chicago Press.

White, D., \& Le Cornu, A. (2011). Visitors and residents: a new typology for online engagement. First Monday, 16(9). doi:10.5210/fm.v16i9.3171

Wright, F., White, D., Hirst, T., \& Cann, A. (2014). Visitors and residents: mapping student attitudes to academic use of social networks. Learning, Media and Technology, 39(1), 126-141.

Yoon, E., \& Eckels, J., (2013). Make these changes to help digital marketing fulfill its potential. HBR Blog Network, http://blogs.hbr.org/2013/05/mahe-these-chngaes-to-hekp-dig/ 